\title{
Update on the biochemistry of chlorophyll breakdown
}

\author{
Hörtensteiner, Stefan
}

\begin{abstract}
In land plants, chlorophyll is broken down to colorless linear tetrapyrroles in a highly conserved multi-step pathway. The pathway is termed the 'PAO pathway', because the opening of the chlorine macrocycle present in chlorophyll catalyzed by pheophorbide a oxygenase (PAO), the key enzyme of the pathway, provides the characteristic structural basis found in all further downstream chlorophyll breakdown products. To date, most of the biochemical steps of the PAO pathway have been elucidated and genes encoding many of the chlorophyll catabolic enzymes been identified. This review summarizes the current knowledge on the biochemistry of the PAO pathway and provides insight into recent progress made in the field that indicates that the pathway is more complex than thought in the past.
\end{abstract}

DOI: https://doi.org/10.1007/s11103-012-9940-Z

Posted at the Zurich Open Repository and Archive, University of Zurich

ZORA URL: https://doi.org/10.5167/uzh-87901

Journal Article

Accepted Version

Originally published at:

Hörtensteiner, Stefan (2013). Update on the biochemistry of chlorophyll breakdown. Plant molecular biology, 82(6):505-517.

DOI: https://doi.org/10.1007/s11103-012-9940-z 


\title{
Update on the Biochemistry of Chlorophyll Breakdown
}

\author{
Stefan Hörtensteiner
}

Institute of Plant Biology

University of Zurich

Zollikerstrasse 107

$\mathrm{CH}-8008$ Zurich

Switzerland

Email: shorten@botinst.uzh.ch

Phone: +41446348282

Fax: +41 446348204 


\begin{abstract}
In land plants, chlorophyll is broken down to colorless linear tetrapyrroles in a highly conserved multistep pathway. The pathway is termed the 'PAO pathway', because the opening of the chlorine macrocycle present in chlorophyll catalyzed by pheophorbide $a$ oxygenase (PAO), the key enzyme of the pathway, provides the characteristic structural basis found in all further downstream chlorophyll breakdown products. To date, most of the biochemical steps of the PAO pathway have been elucidated and genes encoding many of the chlorophyll catabolic enzymes been identified. This review summarizes the current knowledge on the biochemistry of the PAO pathway and provides insight into recent progress made in the field that indicates that the pathway is more complex than thought in the past.
\end{abstract}

Keywords: chlorophyll catabolites; chlorophyll breakdown; detoxification; fruit ripening; leaf senescence

\title{
Introduction
}

Chlorophyll (Chl), the most abundant pigment on Earth, is essential for light absorption during photosynthesis. However, when the photosynthetic apparatus is overexcited, for example under light stress conditions, $\mathrm{Chl}$ can act as a photosensitizer, that can cause cell damage and death (Apel and Hirt 2004). Likewise, defects in Chl biosynthesis and degradation result in cytotoxic effects, which are caused by the accumulation of respective photodynamic metabolic intermediates (Mochizuki et al. 2010; Pružinská et al. 2003). Therefore, tight regulation mechanisms, well known in the case of Chl biosynthesis (Tanaka and Tanaka 2006; Tanaka and Tanaka 2007), are required to prevent these toxic effects. It is evidenced that $\mathrm{Chl}$ breakdown is regulated at different levels to limit the accumulation of photodynamic breakdown intermediates (Park et al. 2007; Hörtensteiner 2006; Sakuraba et al. 2012).

$\mathrm{Chl}$ breakdown does not only occur during leaf senescence and fruit ripening, but also at steady state, during post-harvest and in response to biotic and abiotic stresses, $\mathrm{Chl}$ is turned over or degraded, at least to some extent. However, it remains unknown whether the mechanism of $\mathrm{Chl}$ breakdown under all these conditions is the same. To date the best characterized mechanism is the 'PAO pathway' of Chl breakdown. It is named after pheophorbide a oxygenase (PAO), which accounts for the opentetrapyrrolic backbone structure of different types of $\mathrm{Chl}$ catabolites found in senescent leaves and fruits (Hörtensteiner and Kräutler 2011). Thus, the PAO pathway is active during leaf senescence and in ripening fruits. It can be divided into two parts, (i) reactions on colored intermediates that end in the formation of a primary fluorescent $\mathrm{Chl}$ catabolite $(p \mathrm{FCC})$ and (ii) $p \mathrm{FCC}-$ modifying reactions, that typically 
end with the isomerization of modified FCCs ( $m F C C s)$ to respective nonfluorescent $\mathrm{Chl}$ catabolites (NCCs). These two parts of the pathway are also spatially separated in the cell: formation of $p F C C$ occurs in plastids whereas subsequent modification and isomerization are localized in cytosol and vacuole, respectively.

This review summarizes the biochemistry of the PAO pathway of $\mathrm{Chl}$ breakdown. Some of the newly identified catabolites such as hypermodified FCCs ( $h$ FCCs) (Hörtensteiner and Kräutler 2011) and urobilinogenoidic Chl catabolites (UCCS) (Müller et al. 2011), point to divergent paths of the PAO pathway that might exist in some plant species.

\section{NCCs, the final chlorophyll breakdown products}

The pioneering identification and structure determination of the first (final) Chl breakdown product, a NCC from barley, named Hv-NCC-1, in 1991 (Kräutler et al. 1991) marked a milestone in the elucidation of Chl breakdown, which until then was described as 'biological enigma' (Hendry et al. 1987; Brown et al. 1991). To date more than 15 structures of NCCs have been identified from over 10 plant species. They exhibit an open tetrapyrrole backbone which is identical in all NCCs, but depending on the plant species, NCC patterns can be complex, such as in Arabidopsis thaliana (Arabidopsis) with to date five identified NCCS, or simple with one major NCC, as in the deciduous tree Cercidiphyllum japonicum. The reason for this complexity arises from the fact that NCCs vary with regard to the chemical constitution of one or more of three side positions depicted as $R^{1}$ to $R^{3}$ in Figure 1. Further variability in NCCs is provided by the chiral center of $C 1$, which renders pyrrole ring $A$ in either $R$ or $S$ configuration (Figure 1 ). This depends on the plant species and is the result of the species-specific stereospecificity of red Chl catabolite reductase (RCCR) (Pružinská et al. 2007; Hörtensteiner et al. 2000), which introduced the C1-stereocenter during reduction of red $\mathrm{Chl}$ catabolite (RCC) to $\mathrm{pFCC}$ (see below). Thus, the occurrence of two possible stereoisomers, $p F C C$ and epi-pFCC, ultimately results in C1-isomeric NCCs. With the exception of At-NCC3 from Arabidopsis (Müller et al. 2006), all NCCs identified so far are derived from Chl $a$ as indicated by a methyl group at C7 (Kräutler 2003; Kräutler and Hörtensteiner 2006). This specificity is explained by the fact that conversion of $\mathrm{Chl} b$ to $\mathrm{Chl} a$ is a prerequisite for $\mathrm{Chl}$ breakdown through the PAO pathway (see below).

Having originally been identified from senescing leaves, NCC structure analysis has recently been extended to ripening fruits. The group of B. Kräutler resolved the constitutions of different NCCs from the peels of ripening apples and pears and, in addition, further, so far structurally uncharacterized, NCCS 
were identified in the peels of yellow bananas (Musa cavendish) (Moser et al. 2008a; Müller et al. 2007; Kräutler 2008). These analyses demonstrate that the PAO pathway of Chl breakdown not only occurs during leaf senescence but also during fruit ripening.

NCCs accumulate inside the vacuoles of senescing cells (Matile et al. 1988; Hinder et al. 1996). They are derived from FCCs, which, after vacuolar import (Hinder et al. 1996), rapidly convert to NCCs by an acid-catalyzed isomerization (Oberhuber et al. 2003) (Figure 2). Thus, in contrast to NCCs, FCCs are generally of low abundance in senescing leaves. Despite this, FCCs could be identified in different species (Ginsburg and Matile 1993; Pružinská et al. 2005; Bachmann et al. 1994) and the constitutions of pFCC and of some $m F C C s$ have been resolved (Table 1). Interestingly, within a given plant species, the C1stereochemistry and side modifications found in FCCs and NCCs are identical (Pružinská et al. 2005). This supports the view that modifications of these side positions occur at the level of FCCs. The fluorescence properties of FCCS are due to a Schiff's base $(C=N-C=C)$ configuration of pyrrole ring $D$ and the unsaturated $y$-methine bridge (Figure 1). Upon isomerization of a FCC to its respective NCC this configuration is lost. Interestingly, it has recently been shown that the speed of FCC-to-NCC isomerization is, at least in part, determined by the structural configuration around the isocyclic ring $\mathrm{E}$ (Figure 1); Arabidopsis mes16 mutants that are devoid of MES16, a methyl esterase that specifically demethylates the $\mathrm{C}^{2} 3^{2}$ carboxymethyl group of FCCs (see below), accumulate rather high concentrations of $013^{4}$-methylated FCCs. As a consequence, senescent mes16 leaves strongly fluoresce under UV-light (Christ et al. 2012). Senescent leaves of wild type Arabidopsis mostly accumulate NCCs that are $013^{4}$ desmethylated (Pružinská et al. 2005). In vitro FCC-to-NCC isomerization experiments on pFCC and 0134desmethyl $p F C C$ under slightly acidic conditions demonstrated that the latter was isomerized three-times faster, indicating that a free carboxyl group at $\mathrm{C}^{2} 3^{2}$ promotes the isomerization to a NCC (Christ et al. 2012).

\section{Chlorophyll catabolic enzymes}

Reduction of chlorophyll $b$ to chlorophyll $a$

Except At-NCC-3 (Müller et al. 2006), all FCCs and NCCs and also the newly identified maple UCC (Müller et al. 2011) are derived from Chl $a$. This is explained, at least in part, by the substrate specificity of PAO for pheophorbide (Pheide) $a$ (Hörtensteiner et al. 1995) and suggests that conversion of $\mathrm{Chl} b$ to $\mathrm{Chl} a$ is a prerequisite for further degradation via PAO. However, mutants that are devoid of PAO 
specifically accumulate Pheide $a$ (Tanaka et al. 2003; Pružinská et al. 2003), indicating that conversion of $\mathrm{Chl} b$ to $\mathrm{Chl} a$ occurs upstream of Pheide formation.

$\mathrm{Chl} b$-to-Chl $a$ conversion is carried out in two reductive steps with $\mathrm{C} 7$-hydroxymethyl $\mathrm{Chl} a$ as an intermediate. The two enzymes catalyzing these consecutive reactions, $\mathrm{Chl} b$ reductase and hydroxymethyl $\mathrm{Chl}$ a reductase (HCAR), have different biochemical properties; while the latter is a ferredoxin (Fd)-dependent, stroma-localized enzyme, $\mathrm{Chl} b$ reductase localizes to the thylakoid membrane and requires NADPH as electron source (Ito et al. 1996; Scheumann et al. 1998, 1999). Genes encoding both enzymes have recently been identified (Kusaba et al. 2007; Meguro et al. 2011). In Arabidopsis and rice, $\mathrm{Chl} b$ reductase is encoded by two genes, NON-YELLOW COLORING1 (NYC1) and NYC1-LIKE (NOL) (Horie et al. 2009; Kusaba et al. 2007; Sato et al. 2009). NYC1 and NOL are members of the family of short-chain dehydrogenases/reductases and share around 50\% sequence identity. NYC1 expression correlates with leaf senescence (Kusaba et al. 2007). Rice or Arabidopsis nyc1 mutants exhibit a stay-green phenotype with high retention of light harvesting complex II (LHCII) subunits and Chl $b$ during senescence. This supported the assumption that NYC1 encodes $\mathrm{Chl} b$ reductase, although $\mathrm{Chl} b$ reductase activity could so far not be demonstrated with recombinant NYC1 (Horie et al. 2009; Kusaba et al. 2007). A possible explanation is the hydrophobic nature of NYC1 proteins; they contain three predicted transmembrane spanning domains, fitting the proposed biochemical features of $\mathrm{Chl} b$ reductase. In contrast, rice and Arabidopsis NOL were both shown to exhibit $\mathrm{Chl} b$ reductase activity when expressed in E. coli (Sato et al. 2009; Horie et al. 2009). NOL, although predicted to be a soluble protein, co-purifies with the thylakoid membrane, which is explained by physical interaction between NYC1 and NOL (Sato et al. 2009; Sakuraba et al. 2012). Interestingly, rice NOL mutants have a stay-green phenotype similar to nyc1 mutants, but in Arabidopsis, loss-of-function of NOL does not result in retention of Chl. This indicates that in these two species, NOL could have different roles; in rice NYC1 and NOL are equally important probably by forming a heteromeric complex which is a prerequisite for activity, while in Arabidopsis, NYC1 function seems to be predominate NOL.

HCAR was recently cloned from Arabidopsis (Meguro et al. 2011). It encodes a chloroplast-localized protein that contains an iron-sulfur cluster and a FAD-binding pocket. Recombinant HCAR catalyzed reduction of C7-hydroxymethyl $\mathrm{Chl} a$ to $\mathrm{Chl} a$ in the presence of reduced ferredoxin, in agreement with its proposed biochemical properties (Scheumann et al. 1998). Interestingly, HCAR has high sequence homology to cyanobacterial divinyl reductases (DVRs), which catalyze reduction of the C8 vinyl moiety of divinyl-protochlorophyllide to an ethyl group during $\mathrm{Chl}$ biosynthesis. This indicates that during evolution HCAR was recruited from DVRs to enable $\mathrm{Chl} b$ to $\mathrm{Chl} a$ conversion in algae and land plants (Meguro et al. 2011). 
Mg-dechelation and dephytylation

Pheide $a$ has been identified as a genuine intermediate of Chl breakdown (Langmeier et al. 1993; Vicentini et al. 1995a) and the establishment of an in vitro assay that converts Pheide $a$ to pFCC in an PAO-dependent manner (Hörtensteiner et al. 1995) demonstrated that removal of phytol and the central magnesium atom of $\mathrm{Chl}$ precedes the chlorine ring opening reaction of PAO. Until recently, uncertainty existed about the order of these two reactions, with phytol removal preceding Mg-chelation being the favored hypothesis (Tanaka and Tanaka 2006; Hörtensteiner 2006). In agreement with this, chlorophyllase, which hydrolyzes phytol from Chl, was believed to be active during senescence-related Chl breakdown (Takamiya et al. 2000). Chlorophyllase genes (CLH) were cloned from different species including Arabidopsis and in all cases chlorophyllase activity could indeed be demonstrated with the recombinant enzymes (Tsuchiya et al. 1999; Jakob-Wilk et al. 1999; Arkus et al. 2005; Tang et al. 2004; Chen et al. 2008). Some of the cloned CLHs were predicted to localize outside the chloroplast, i.e. in the cytosol or the vacuole, and subsequent localization experiments gave ambiguous results. For example, the two Arabidopsis CLHs, AtCLH1 and AtCLH2, localized to the cytosol when tagged with GFP (Schenk et al. 2007), while lemon CLH was shown by in situ immunofluorescence to reside inside the chloroplast in lemon flavedo tissue and to co-purify with chloroplast membranes after heterologous expression in tobacco mesophyll protoplasts (Harpaz-Saad et al. 2007; Azoulay Shemer et al. 2008). Contradictory results were also obtained in experiments with de-regulated CLH expression; absence of AtCLH1 and/or AtCLH2 in respective mutants (Schenk et al. 2007) as well as silencing of AtCLH1 (Kariola et al. 2005) or AtCLH2 (Liao et al. 2007) had little effect on senescence-related Chl breakdown, while antisensesuppression of broccoli CLH delayed rates of postharvest broccoli head yellowing (Chen et al. 2008). Furthermore, expression patterns of neither AtCLHs nor CLHs of broccoli or Chinese flowering cabbage correlate with Chl breakdown (Liao et al. 2007; Zimmermann et al. 2004; Büchert et al. 2011; Zhang et al. 2011). By contrast, CLH was convincingly shown to participate in Chl breakdown during fruit ripening of Citrus species (Azoulay Shemer et al. 2008; Harpaz-Saad et al. 2007). Further analysis is demanded to elucidate the role of CLHs in leaves and fruits, ideally in a plant species that allows simultaneous analysis of leaf senescence and fruit ripening, such as tomato.

Recently three independent groups (Schelbert et al. 2009; Ren et al. 2010; Morita et al. 2009) succeeded in identifying a candidate esterase for phytol cleavage in Arabidopsis and rice, and in one case was the recombinant Arabidopsis enzyme biochemically analyzed (Schelbert et al. 2009). It exhibited esterase activity towards Pheophytin (Phein) $a$ or Phein $b$, yielding the respective Pheide pigment, but 
did not accept Chls as substrate. This pointed to an intriguing specificity towards metal-free pigments and the enzyme was therefore termed pheophytin pheophorbide hydrolase (pheophytinase; PPH). Consistent with this, Arabidopsis pph mutants accumulated Phein during leaf senescence (Schelbert et al. 2009). Arabidopsis PPH, alternatively named CRN1 by Ren et al. (2010), and its rice ortholog, termed NCY3 (Morita et al. 2009), were shown to localize to the chloroplast and deficiency in respective mutants caused a stay-green phenotype. In summary, there is striking evidence that during leaf senescence, at least in Arabidopsis, dephytylation occurs after Mg removal, by the Phein-specific action of PPH.

The mechanism of Mg-dechelation has not been resolved in detail until now. Different types of activities have been described in the past, one attributed to a heat-stable low-molecular weight compound, termed metal-chelating substance (MCS) (Shioi et al. 1996a; Suzuki and Shioi 2002), the other attributed to heat-labile proteins, termed Mg-releasing proteins (MRP) (Suzuki and Shioi 2002; Vicentini et al. 1995b). However, MRP activity could so far only been shown when using chlorophyllin, i.e. an artificial form of $\mathrm{Chl}$, as substrate, but not with Chlide. This was interpreted as MCS being active in vivo (Kunieda et al. 2005). Considering the fact that Mg-dechelation likely occurs before dephytylation (Schelbert et al. 2009), it is possible that Chlide is not the natural substrate for Mg-dechelation. Therefore, re-examination of MCS and MRP-like activities with Chl as substrate is demanded. Recently, an Arabidopsis gene, At5g17450, was proposed as a candidate for MCS. At5g17450 was identified to be co-expressed, together with PPH and PAO, with proteins that localize to plastoglobules (Lundquist et al. 2012). Plastoglobules are thylakoid-associated lipoprotein particles that are suggested to have an important role in lipid metabolism during different developmental phases, but particularly during senescence (Bréhélin et al. 2007).

Pheophorbide $a$ oxygenase

PAO is a Rieske-type monooxygenase (Pružinská et al. 2003; Hörtensteiner et al. 1998), which contains an additional mononuclear iron center that is responsible for the activation of molecular oxygen (Schmidt and Shaw 2001). Electrons required to supply the iron-redox cycle of PAO are provided by reduced ferredoxin (Ginsburg et al. 1994; Pružinská et al. 2003). PAO proteins contain two C-terminally located transmembrane domains and based on the distribution of its activity, PAO was considered to localize to the chloroplast envelope (Matile and Schellenberg 1996). However, recent re-examination using PAO-green fluorescent protein analysis and immunoblot analysis of chloroplast membrane fractions separated by sucrose density gradients demonstrated PAO to reside in the thylakoid membrane (Sakuraba et al. 2012). As mentioned above, PAO exhibits an intriguing specificity for Pheide $a$, with 
Pheide $b$ being a competitive inhibitor. In 2003, two groups succeeded in identifying Arabidopsis PAO at the molecular level (Pružinská et al. 2003; Tanaka et al. 2003). PAO is identical to ACCELERATED CELL DEATH (ACD) 1 (Greenberg and Ausubel 1993) and the ortholog of LETHAL LEAF SPOT 1 in maize (Gray et al. 1997). The absence of PAO in mutants or antisense lines from different plant species results in premature cell death (Gray et al. 2002; Pružinská et al. 2003; Pružinská et al. 2005; Greenberg and Ausubel 1993; Tanaka et al. 2003; Spassieva and Hille 2002). Phototoxicity of Pheide $a$, which was shown in many cases to accumulate to high concentrations, is considered to trigger the observed cell death phenotype in a light-dependent manner (Pružinská et al. 2005). However, Arabidopsis PAO-antisense lines were recently shown to exhibit light-independent cell death and a cell death signaling mechanism involving Pheide $a$ was proposed (Hirashima et al. 2009). Components of such a pathway have not yet been identified.

Red chlorophyll catabolite reductase

As mentioned above, RCCR catalyzes the $C 1 / C 20$ reduction of $R C C$ to $p F C C . R C C R$ is a soluble protein of about $30 \mathrm{kDa}$ and, like for PAO, electrons are supplied from reduced ferredoxin. RCCR is distantly related to a family of ferredoxin-dependent bilin reductases (FDBR) (Frankenberg et al. 2001) and the recent elucidation of the crystal structures of Arabidopsis RCCR (AtRCCR) in the absence and presence of RCC confirmed a high degree of structural similarity to these FDBRs (Sugishima et al. 2009; Sugishima et al. 2010). For the FDBRs, a reaction mechanism has been proposed that involves direct transfer of an electron from ferredoxin to the substrate giving rise to a tetrapyrrole radical intermediate, followed by substrate protonation through a highly conserved glutamate residue present in the FDBRs (Tu et al. 2008; Tu et al. 2004). A similar radical mechanism and involvement of a glutamate residue (glutamate ${ }_{154}$ of AtRCCR) have also been proposed for RCCR (Sugishima et al. 2009), and site-directed mutagenesis confirmed the requirement of glutamate ${ }_{154}$ of AtRCCR for in vitro and in vivo activity (Pattanayak et al. 2012).

The above-mentioned, highly stereospecific formation of $p F C C$, yielding one of two possible C1stereoisomers, $p F C C$ or epi-pFCC, is defined by RCCR. The analysis of RCCRs from more than 50 plant species (Hörtensteiner et al. 2000; Pružinská et al. 2007), demonstrated presence of either type-1 (forming $p F C C$ ) or type-2 (forming epi-pFCC) RCCR in a given species. This specificity was analyzed in vitro with chimeric proteins produced between Arabidopsis (type-1) and tomato RCCR (type-2). This analysis identified phenylalanine 218 of AtRCCR as crucial for stereospecificity; when changed to valine (as present in tomato RCCR), AtRCCR was switched from pFCC to epi-pFCC production (Pružinská et al. 2007). 
Interestingly, phenylalanine 218 is located within the RCC binding pocket in the crystal structure of AtRCCR (Sugishima et al. 2009), but structure analysis of the variant with valine at position 218 did not convincingly explain the altered stereospecificity (Sugishima et al. 2010).

RCCR was molecularly identified more than ten years ago (Wüthrich et al. 2000) and was shown to be identical to ACD2 (Greenberg et al. 1994; Mach et al. 2001). acd2 mutants develop a cell death phenotype which highly correlates with the accumulation of RCC and RCC-like pigments (Pružinská et al. 2007). Cell death is light-dependent and coincides with the production of singlet oxygen (Pattanayak et al. 2012). However, the fact that cell death in acd2 also occurred in Chl-free root protoplasts, called into question the role of RCCR/ACD2 as a Chl catabolic enzyme (Yao and Greenberg 2006). Complementation of $\operatorname{acd} 2$ with AtRCCR enzymes that exhibited different C1-stereospecificities as outlined above, resulted in corresponding stereospecifically uniform patterns of catabolites (Pružinská et al. 2007). This clearly demonstrated in vivo participation of RCCR in Chl breakdown during senescence.

RCCR was experimentally shown to localize to the chloroplast (Wüthrich et al. 2000), but it also partially localizes to mitochondria, particularly upon stresses, such as pathogen infection or protoporphyrin IX treatment (Yao and Greenberg 2006). In addition, cell death in acd 2 involves an early mitochondrial oxidative burst (Yao et al. 2004). Mitochondrial localization of ACD2 was believed to play a role in preventing this oxidative burst (Yao and Greenberg 2006) and indeed, specific and exclusive targeting of ACD2 to mitochondria rescues the cell death phenotype of acd2 (Pattanayak et al. 2012). The mechanism of this protection has not been resolved yet, but it is speculated that pro-cell death signals, i.e. possibly RCC, could be mobile in the cell to trigger cell death via mitochondria and mitochondrial-localized ACD2/RCCR could detoxify this signal (Pattanayak et al. 2012).

$\mathrm{C} 13^{2}$-methylester hydrolysis

The diversity of FCCS, NCCS and the novel UCC identified in maple indicate that many different enzymatic reactions occur downstream of $p \mathrm{FCC}$ (or epi-pFCC). For example, in Arabidopsis at least three steps are required to account for the five NCCs found in this species. However, to date only the enzyme hydrolyzing the $\mathrm{C} 13^{2}$-methylester has been identified at the molecular level. $\mathrm{C} 13^{2}$-demethylated catabolites have so far only been identified in the Brassicaceae, and in the past an enzyme termed pheophorbidase has been described, which is capable of hydrolyzing the $\mathrm{C}^{2} 3^{2}$-methylester of Pheide (Suzuki et al. 2006). The product of the reaction, C132-carboxyl pyropheophorbide, was shown to spontaneously decarboxylate to pyropheophorbide (Shioi et al. 1996b), a proposed product of Chl breakdown mainly found in algae and during post harvest senescence (Ziegler et al. 1988; Aiamla-or et 
al. 2010). Pheophorbidase was cloned from Raphanus sativus (Suzuki et al. 2006); it is a serine-type esterase and is highly similar to the members of the Arabidopsis methyl esterase (MES) protein family. In a recent study (Christ et al. 2012), recombinant MES16 was shown to hydrolyze the $\mathrm{C} 13^{2}$ methylester of both Pheide $a$ and pFCC (or epi-pFCC), but not of a NCC. However, MES16 localized to the cytosol and was specifically active on FCCS in vivo. Consequently, mes16 mutants exclusively formed $013^{4}$ methylated FCCS and NCCs. Specific action on the level of FCCs was confirmed by chloroplast mislocalization of MES16 in pao1, an Arabidopsis mutant deficient in PAO; while pao1 specifically accumulated Pheide (Pružinská et al. 2005; Tanaka et al. 2003), chloroplast-localization of MES16 caused the accumulation of mainly pyropheophorbide during senescence. This indicated that, although MES16 could theoretically act on Pheide, different localization of Pheide (in the chloroplast) and MES16 (in the cytosol) disables contact between them in vivo (Christ et al. 2012).

\section{The stay-green protein}

In many plant species, stay-green mutants have been identified that show retention of $\mathrm{Chl}$ during senescence. As mentioned above, mutations in PPH or NYC1 show such stay-green phenotypes. However, many stay-green mutants from different species are defective in another gene, termed STAYGREEN (SGR). Among them are mutants of bell pepper, tomato, rice, meadow fescue, Arabidopsis (termed nye1) as well as Gregor Mendel's famous green cotyledon mutant of pea [for a recent review, see Hörtensteiner (2009)]. It is likely that molecular defects in SGR are present in further stay-green mutants, such as soybean $d_{1} d_{2}$ (Guiamét et al. 1991) and Arabidopsis ore10 (Oh et al. 2003).

SGR proteins from different species are highly similar and localize to the chloroplast (Hörtensteiner 2009; Park et al. 2007; Sato et al. 2007; Ren et al. 2007). However, a function for SGR remains uncertain. SGR has been shown to physically interact with known Chl catabolic enzymes (CCEs), i.e. NYC1, NOL, PPH, PAO and RCCR, and to also specifically interact with LHCIl subunits of the photosynthetic apparatus. At the same time, CCEs interacted among each other and also with LHCII (Sakuraba et al. 2012). Although a stable high molecular weight complex containing all protein components could not be demonstrated, these findings pointed to the possibility of SGR being required to recruit CCEs to the thylakoid membrane as a prerequisite for $\mathrm{Chl}$ breakdown. CCE protein-protein interaction at the thylakoid membrane might allow metabolic channeling of $\mathrm{Chl}$ and its degradation intermediates to prevent possible pigment phototoxicity. When physical interaction between PAO and RCCR, as an example, was analyzed by bimolecular fluorescence complementation in Arabidopsis protoplasts, interaction could be 
demonstrated in wild type protoplasts, but not in nye1 protoplasts, i.e. in the absence of SGR. This points to a crucial structural rather than direct biochemical role for SGR in Chl breakdown.

Besides exhibiting a leaf stay-green phenotype, a Medicago truncatula SGR mutant was also affected in nodule senescence (Zhou et al. 2011). This surprising finding indicates that the role of SGR may go beyond its requirement for $\mathrm{Chl}$ breakdown; it possibly could have a more general role in nitrogen remobilization, maybe by recruiting proteases for the degradation of protein (complexes) during senescence. In line with this is the fact that all SGR mutants analyzed so far, retain high levels of LHCII subunits (Aubry et al. 2008; Jiang et al. 2007) and a role of SGR in destabilizing Chl-binding protein complexes as a prerequisite for the subsequent degradation of apoproteins and $\mathrm{Chl}$ has been suggested (Park et al. 2007; Hörtensteiner 2009). In Arabidopsis, levels of SGR were shown to positively correlate with the extent of development of disease or hypersensitive response symptoms during Pseudomonas syringae infections (Mur et al. 2010; Mecey et al. 2011) and phototoxic Pheide $a$ was considered to contribute to cell death execution (Mur et al. 2010). These results are in agreement with the light dependency shown for several plant-pathogen interactions and indicate a link between plant responses to pathogen infections and $\mathrm{Chl}$ breakdown.

\section{Subcellular localization of the pathway}

The early reactions of the PAO pathway of $\mathrm{Chl}$ breakdown, i.e. at least up to the formation of $p \mathrm{FCC}$ or epi-pFCC, take place in senescing chloroplasts (termed gerontoplasts) (Figure 2). In line with this is the observation that intact isolated gerontoplasts are capable of synthesizing $p$ FCC (Matile et al. 1992). In addition to $p F C C$, gerontoplasts produce a second more polar FCC (Ginsburg et al. 1994; Schellenberg et al. 1990), which most likely represents the C8-hydroxylated form of $p$ FCC (B. Christ and S. Hörtensteiner, unpublished). C8-hydroxylation is found in most FCCs and NCCs structurally characterized so far (Table 1), indicating this modification to be a common reaction of the PAO pathway present in all plant species. By contrast, all further side modifications are species-specific and, as far as they have been characterized (Hörtensteiner 1998; Christ et al. 2012), are indicated to take place in the cytosol. This implies that pFCC or C8-hydroxyl-pFCC is exported from gerontoplasts. Release of FCCs has been studied in isolated organelles and was shown to require the (extra-plastidial) presence of ATP or UTP (Matile et al. 1992). The molecular nature of $\mathrm{Chl}$ catabolite transporter(s) at the chloroplast envelope is unknown, however it is interesting to note that its specificity likely is restricted to linear tetrapyrrole-type catabolites, i.e. RCCs and FCCs. This is deduced from the observation that acd 2 mutants accumulate RCCs in the vacuole 
(Pružinská et al. 2007). On the other hand, Pheide $a$ accumulating in pao1 is not demethylated by cytosol-localized MES16, but when MES16 is mis-localized to the plastid $013^{4}$-demethylation occurs, indicating Pheide to be retained within the gerontoplast (Christ et al. 2012).

Based on their primary amino acid sequence and from biochemical studies, plastid-located CCEs were considered to localize to different sub-chloroplast fractions, i.e. thylakoid (NYC1), stroma (NOL, PPH, RCCR) and envelope (PAO) (Scheumann et al. 1999; Sato et al. 2009; Rodoni et al. 1997; Matile and Schellenberg 1996; Schelbert et al. 2009). As a consequence, Chl pigment shuttling mechanisms between the thylakoid and the envelope have been postulated in the past (Matile et al. 1999; Hörtensteiner 2006). As mentioned above, a detailed study on protein-protein interaction among SGR and CCES demonstrated that SGR and all CCEs (including PAO) attach to the thylakoid membrane during Chl breakdown (Sakuraba et al. 2012). They possibly form a dynamic multi-protein complex together with LHCII, which likely allows metabolic channeling of phototoxic Chl breakdown intermediates upstream of nontoxic $p$ FCC (Figure 2).

Final Chl catabolites are deposited in the vacuoles of senescing cells (Matile et al. 1988; Hinder et al. 1996). This is certainly true for NCCs, which have been shown to arise from respective FCCs through isomerization catalyzed by the acidic vacuolar sap (Oberhuber et al. 2003). Transport across the tonoplast has been shown to be a primary active process (Hinder et al. 1996), implying the involvement of ATP binding cassette (ABC) type transporters. After expression in yeast, two Arabidopsis transporters, $A B C C 2$ and $A B C C 3$, were shown to be capable of transporting a NCC from canola (Lu et al. 1998; Tommasini et al. 1998). However, an Arabidopsis $A B C C 2$ mutant was only marginally affected in senescence (Frelet-Barrand et al. 2008), pointing to a possible functional redundancy of different transporters.

\section{Gene regulation}

$\mathrm{Chl}$ breakdown is an integral process of leaf senescence, however it is only part of a plethora of structural changes and metabolic processes that are turned on during leaf senescence. Collectively, these processes are termed the 'senescence syndrome' (Lim et al. 2007). Initiation and progression of the syndrome is executed by a complex regulatory network, but to date only a few transcriptional regulators have been identified (Uauy et al. 2006; Wu et al. 2012; Guo and Gan 2006). Transcriptional regulation of $\mathrm{Chl}$ breakdown is an integral process within this network. Thus, genes for SGR and most of the CCEs are up-regulated during leaf senescence, independent of the mode of senescence induction 
(Buchanan-Wollaston et al. 2005; Van der Graaff et al. 2006; Breeze et al. 2011). Furthermore, the transcriptionally regulated genes of the PAO pathway, i.e. SGR, NYC1, PPH, PAO and MES16 (Ren et al. 2007; Ren et al. 2010; Schelbert et al. 2009; Pružinská et al. 2005; Horie et al. 2009; Christ et al. 2012) are highly co-regulated in Arabidopsis and consequently cluster closely together when performing gene network analyses, for example using the ATTEDII platform (Obayashi et al. 2009). Possibly, among the hundreds of transcription factors that have been shown to be up-regulated during leaf senescence (Balazadeh et al. 2008) are some that specifically target the PAO pathway, but these have so far not been identified.

Variations of the PAO pathway: new types of 'final' chlorophyll catabolites

\section{Hypermodified FCCs}

New types of FCC, termed hypermodified FCCs ( $h$ FCCs) were recently identified in ripening banana fruits and in senescent banana and peace lily leaves (Banala et al. 2010; Moser et al. 2008a; Moser et al. 2009; Kräutler et al. 2010). In contrast to the transient occurrence of $m F C C s$ as intermediary catabolites in senescing leaves that are converted to NCCs (see above), $h$ FCCs persist in ripening or senescing tissues. This is explained by the structure of these FCCs with the $\mathrm{C} 17$ propionic acid group being conjugated with different moieties (Table 1). As a likely consequence of these C17-modifications, the acid-induced isomerization to NCCs does not occur (Moser et al. 2009), likely because, as proposed by Oberhuber at al. (2003), a free propionic acid side chain at C17 is required for this isomerization. However, it remains to be shown whether hFCCs, like NCCs, indeed accumulate inside the vacuole (Figure 2). The identification of $h$ FCCs indicates the existence of a second variant fate of Chl catabolites within the PAO pathway, i.e. C17-modified catabolites persist as FCCs, whereas unmodified ones are converted to NCCs. Interestingly, in banana and peace lily, both NCCs and hFCCs occur simultaneously pointing to the possibility that $h$ FCCs might have some, so far unidentified, physiological role (Moser et al. 2009).

UCC, a new type of final chlorophyll catabolite?

In many plant species abundance of NCCs was shown to increase with senescence progression. This supports the view that NCCs (and in some species hFCCs) are the final products of Chl breakdown. However, in a recent study on senescent maple leaves, a new type of Chl-derived linear tetrapyrrole has 
been identified as the sole $\mathrm{Chl}$ catabolite accumulating to amounts that represent more than $50 \%$ of the original Chl present in green maple leaves (Müller et al. 2011). Structure analysis demonstrated this catabolite to exhibit an urobilinogenoidic constitution, i.e. the $\alpha$-methine carbon that bridges pyrroles $\mathrm{A}$ and $\mathrm{B}$ in $\mathrm{Chl}$ and that is retained in FCCs and NCCs as a formyl group attached to ring B is absent in this new catabolite, which is therefore tentatively termed urobilinogenoidic Chl catabolite (UCC) (Figure 1). Interestingly, an UCC that is structurally related to Hv-NCC-1 has been identified in small amounts in senescent barley leaves and it was speculated to be a degradation product of the latter possibly occurring by unspecific oxidation (Losey and Engel 2001). However, the maple UCC differs from all so far analyzed NCCs by an opposite stereochemistry at the $\gamma$-methine carbon, indicating it to derive from an upstream intermediate of $\mathrm{Chl}$ breakdown rather than being a degradation product of a (so far unknown) maple NCC (Müller et al. 2011). This indicates that in maple, a divergent path of the PAO pathway might exist that ends in the formation of UCCs and not NCCs as final degradation products of Chl. It remains to be demonstrated to which extend UCCs represent final $\mathrm{Chl}$ catabolites also in other plant species and whether they also accumulate inside the vacuole (Figure 2).

\section{Conclusions and outlook}

With the resolution of the first structure of a final $\mathrm{Chl}$ catabolite twenty years ago (Kräutler et al. 1991) light begun to be shed on the 'biological enigma' of Chl breakdown. Today, the core steps of the PAO pathway have been characterized biochemically and at the molecular level, and respective catabolic intermediates and end products have been identified and structurally characterized from different plant species. Genes for SGR and CCEs are commonly present in land plants, indicating that the PAO pathway is highly conserved from higher plants down to moss. Comparison of CCEs to available genomic sequences of lower plants indicate that RCCR-, PPH- and/or PAO-like proteins might also be present in algae and cyanobacteria (Schelbert et al. 2009; Gray et al. 2004; Pružinská et al. 2007; Thomas et al. 2009), however it remains to be demonstrated whether any of these homologs indeed encodes catalytically active CCEs.

Despite the major progress made recently, several aspects of $\mathrm{Chl}$ breakdown remain to be solved. The surprising recent identification of an UCC as the sole degradation product of $\mathrm{Chl}$ in maple and of persistent $h$ FCCs e.g. in banana implies that the PAO pathway is more complex than the proposed linear conversion of Chl to NCCs would have implied. An intriguing possibility is that Chl catabolites could not merely be by-products of $\mathrm{Chl}$ detoxification, but might also have some other biological role 
(Hörtensteiner and Kräutler 2011). NCCs have high antioxidative potential (Müller et al. 2007), and $h$ FCCS contribute to the optical appearance of leaves and fruits (Kräutler et al. 2010; Moser et al. 2009). In addition, a naturally occurring oxidation product of the major NCC of $C$. japonicum is yellow colored and contributes to the autumnal leaf color in this deciduous tree (Moser et al. 2008b). However, biological roles for $\mathrm{Chl}$ catabolites remain to be experimentally proven. A further future challenge from a biochemical perspective is the molecular identification of the enzymes that convert $p F C C$ to $m F C C s$, $h$ FCCs and/or UCCs. Except MES16 (Christ et al. 2012), none of the respective genes have been cloned. Regarding the core part of the PAO pathway, i.e. Chl-to-pFCC conversion, the mechanism of Mgdechelation is unclear and remains to be elucidated at the molecular level. Likewise, although transport of $\mathrm{Chl}$ catabolites at both the chloroplast envelope and the tonoplast have biochemically been demonstrated, the molecular nature of the transporters is unknown. In summary, future research is demanded to uncover all aspects of the multi-faceted PAO pathway and to fully understand its possible physiological roles.

\section{Acknowledgements}

I would like to thank Bernhard Kräutler from the University of Innsbruck, Austria for many stimulating discussions and the long-term and extremely fruitful collaboration between his and my own group. My work on chlorophyll breakdown is financially supported by grants from the Swiss National Science Foundation, the National Center of Competence in Research Plant Survival, a research program of the Swiss National Science Foundation, and CropLife, an European FP7 Marie-Curie Initial Training Network project.

\section{References}

Aiamla-or S, Kaewsuksaeng S, Shigyo M, Yamauchi N (2010) Impact of UV-B irradiation on chlorophyll degradation and chlorophyll-degrading enzyme activities in stored broccoli (Brassica oleracea $\mathrm{L}$. Italica Group) florets. Food Chem 120:645-651

Apel K, Hirt H (2004) Reactive oxygen species: Metabolism, oxidative stress, and signal transduction. Annu Rev Plant Biol 55:373-399

Arkus KAJ, Cahoon EB, Jez JM (2005) Mechanistic analysis of wheat chlorophyllase. Arch Biochem Biophys 438:146-155 
Aubry S, Mani J, Hörtensteiner S (2008) Stay-green protein, defective in Mendel's green cotyledon mutant, acts independent and upstream of pheophorbide a oxygenase in the chlorophyll catabolic pathway. Plant Mol Biol 67:243-256

Azoulay Shemer T, Harpaz-Saad S, Belausov E, Lovat N, Krokhin O, Spicer V, Standing KG, Goldschmidt EE, Eyal Y (2008) Citrus chlorophyllase dynamics at ethylene-induced fruit color-break; a study of chlorophyllase expression, post-translational processing kinetics and in-situ intracellular localization. Plant Physiol 148:108-118

Bachmann A, Fernández-López J, Ginsburg S, Thomas H, Bouwcamp JC, Solomos T, Matile P (1994) Staygreen genotypes of Phaseolus vulgaris L.: chloroplast proteins and chlorophyll catabolites during foliar senescence. New Phytol 126:593-600

Balazadeh S, Riaño-Pachón DM, Mueller-Roeber B (2008) Transcription factors regulating leaf senescence in Arabidopsis thaliana. Plant Biol 10 (Suppl. 1):63-75

Banala S, Moser S, Müller T, Kreutz CR, Holzinger A, Lütz C, Kräutler B (2010) Hypermodified fluorescent chlorophyll catabolites: source of blue luminescence in senescent leaves. Angew Chem Int Ed 49:5174-5177

Berghold J, Breuker K, Oberhuber M, Hörtensteiner S, Kräutler B (2002) Chlorophyll breakdown in spinach: on the structure of five nonfluorescent chlorophyll catabolites. Photosynth Res 74:109119

Berghold J, Eichmüller C, Hörtensteiner S, Kräutler B (2004) Chlorophyll breakdown in tobacco: on the structure of two nonfluorescent chlorophyll catabolites. Chem Biodivers 1:657-668

Berghold J, Müller T, Ulrich M, Hörtensteiner S, Kräutler B (2006) Chlorophyll breakdown in maize: on the structure of two nonfluorescent chlorophyll catabolites. Monatsh Chem 137:751-763

Breeze E, Harrison E, McHattie S, Hughes L, Hickman R, Hill C, Kiddle S, Kim YS, Penfold CA, Jenkins D, Zhang C, Morris K, Jenner C, Jackson S, Thomas B, Tabrett A, Legaie R, Moore JD, Wild DL, Ott S, Rand D, Beynon J, Denby K, Mead A, Buchanan-Wollaston V (2011) High-resolution temporal profiling of transcripts during Arabidopsis leaf senescence reveals a distinct chronology of processes and regulation. Plant Cell 23:873-894

Bréhélin C, Kessler F, van Wijk KJ (2007) Plastoglobules: versatile lipoprotein particles in plastids. Trends Plant Sci 12:260-266

Brown SB, Houghton JD, Hendry GAF (1991) Chlorophyll breakdown. In: Scheer H (ed) Chlorophylls. CRC Press, Boca Raton, pp 465-489

Buchanan-Wollaston V, Page T, Harrison E, Breeze E, Lim PO, Nam HG, Lin JF, Wu SH, Swidzinski J, Ishizaki $\mathrm{K}$, Leaver CJ (2005) Comparative transcriptome analysis reveals significant differences in gene 
expression and signalling pathways between developmental and dark/starvation-induced senescence in Arabidopsis. Plant J 42:567-585

Büchert AM, Civello PM, Martínez GA (2011) Chlorophyllase versus pheophytinase as candidates for chlorophyll dephytilation during senescence of broccoli. J Plant Physiol 168:337-343

Chen LFO, Lin CH, Kelkar SM, Chang YM, Shaw JF (2008) Transgenic broccoli (Brassica oleracea var. italicia) with antisense chlorophyllase (BoCLH1) delays postharvest yellowing. Plant Sci 174:25-31

Christ B, Schelbert S, Aubry S, Süssenbacher I, Müller T, Kräutler B, Hörtensteiner S (2012) MES16, a member of the methylesterase protein family, specifically demethylates fluorescent chlorophyll catabolites during chlorophyll breakdown in Arabidopsis. Plant Physiol 158:628-641

Curty C, Engel N (1996) Detection, isolation and structure elucidation of a chlorophyll $a$ catabolite from autumnal senescent leaves of Cercidiphyllum japonicum. Phytochemistry 42:1531-1536

Frankenberg N, Mukougawa K, Kohchi T, Lagarias JC (2001) Functional genomic analysis of the HY2 family of ferredoxin-dependent bilin reductases from oxygenic photosynthetic organisms. Plant Cell 13:965-978

Frelet-Barrand A, Kolukisaoglu HU, Plaza S, Rüffer M, Azevedo L, Hörtensteiner S, Marinova K, Weder B, Schulz B, Klein M (2008) Comparative mutant analysis of Arabidopsis ABCC-type ABC transporters: AtMRP2 contributes to detoxification, vacuolar organic anion transport and chlorophyll degradation. Plant Cell Physiol 49:557-569

Ginsburg S, Matile P (1993) Identification of catabolites of chlorophyll porphyrin in senescent rape cotyledons. Plant Physiol 102:521-527

Ginsburg S, Schellenberg M, Matile P (1994) Cleavage of chlorophyll-porphyrin. Requirement for reduced ferredoxin and oxygen. Plant Physiol 105:545-554

Gray J, Close PS, Briggs SP, Johal GS (1997) A novel suppressor of cell death in plants encoded by the L/s1 gene of maize. Cell 89:25-31

Gray J, Janick-Bruckner D, Bruckner B, Close PS, Johal GS (2002) Light-dependent death of maize Ils1 cells is mediated by mature chloroplasts. Plant Physiol 130:1894-1907

Gray J, Wardzala E, Yang M, Reinbothe S, Haller S, Pauli F (2004) A small family of LLS1-related non-heme oxygenases in plants with an origin amongst oxygenic photosynthesizers. Plant Mol Biol 54:39-54

Greenberg JT, Ausubel FM (1993) Arabidopsis mutants compromised for the control of cellular damage during pathogenesis and aging. Plant J 4:327-341

Greenberg JT, Guo A, Klessig DF, Ausubel FM (1994) Programmed cell death in plants: a pathogentriggered response activated coordinately with multiple defense functions. Cell 77:551-563 
Guiamét JJ, Schwartz E, Pichersky E, Noodén LD (1991) Characterization of cytoplasmic and nuclear mutations affecting chlorophyll and chlorophyll-binding proteins during senescence in soybean. 96:227-231

Guo YF, Gan SS (2006) AtNAP, a NAC family transcription factor, has an important role in leaf senescence. Plant J 46:601-612

Harpaz-Saad S, Azoulay T, Arazi T, Ben-Yaakov E, Mett A, Shiboleth YM, Hörtensteiner S, Gidoni D, Gal-On A, Goldschmidt EE, Eyal Y (2007) Chlorophyllase is a rate-limiting enzyme in chlorophyll catabolism and is posttranslationally regulated. Plant Cell 19:1007-1022

Hendry GAF, Houghton JD, Brown SB (1987) The degradation of chlorophyll - A biological enigma. New Phytol 107:255-302

Hinder B, Schellenberg M, Rodoni S, Ginsburg S, Vogt E, Martinoia E, Matile P, Hörtensteiner S (1996) How plants dispose of chlorophyll catabolites. Directly energized uptake of tetrapyrrolic breakdown products into isolated vacuoles. J Biol Chem 271:27233-27236

Hirashima M, Tanaka R, Tanaka A (2009) Light-independent cell death induced by accumulation of pheophorbide $a$ in Arabidopsis thaliana. Plant Cell Physiol 50:719-729

Horie Y, Ito H, Kusaba M, Tanaka R, Tanaka A (2009) Participation of chlorophyll $b$ reductase in the initial step of the degradation of light-harvesting chlorophyll $a / b$-protein complexes in Arabidopsis. J Biol Chem 284:17449-17456

Hörtensteiner S (1998) NCC malonyltransferase catalyses the final step of chlorophyll breakdown in rape (Brassica napus). Phytochemistry 49:953-956

Hörtensteiner S (2006) Chlorophyll degradation during senescence. Annu Rev Plant Biol 57:55-77

Hörtensteiner S (2009) Stay-green regulates chlorophyll and chlorophyll-binding protein degradation during senescence. Trends Plant Sci 14:155-162

Hörtensteiner S, Kräutler B (2011) Chlorophyll breakdown in higher plants. Biochem Biophys Acta 1807:977-988

Hörtensteiner S, Rodoni S, Schellenberg M, Vicentini F, Nandi OI, Qiu Y-L, Matile P (2000) Evolution of chlorophyll degradation: the significance of RCC reductase. Plant Biol 2:63-67

Hörtensteiner S, Vicentini F, Matile P (1995) Chlorophyll breakdown in senescent cotyledons of rape, Brassica napus L.: enzymatic cleavage of phaeophorbide $a$ in vitro. New Phytol 129:237-246

Hörtensteiner S, Wüthrich KL, Matile P, Ongania K-H, Kräutler B (1998) The key step in chlorophyll breakdown in higher plants. Cleavage of pheophorbide $a$ macrocycle by a monooxygenase. J Biol Chem 273:15335-15339 
Ito $\mathrm{H}$, Ohysuka T, Tanaka A (1996) Conversion of chlorophyll $b$ to chlorophyll $a$ via 7-hydroxymethyl chlorophyll. J Biol Chem 271:1475-1479

Iturraspe J, Moyano N, Frydman B (1995) A new 5-formylbilinone as the major chlorophyll $a$ catabolite in tree senescent leaves. J Org Chem 60:6664-6665

Jakob-Wilk D, Holland D, Goldschmidt EE, Riov J, Eyal Y (1999) Chlorophyll breakdown by chlorophyllase: isolation and functional expression of the Chlase1 gene from ethylene-treated Citrus fruit and its regulation during development. Plant J 20:653-661

Jiang H, Li M, Liang N, Yan H, Wei Y, Xu X, Liu J, Xu Z, Chen F, Wu G (2007) Molecular cloning and function analysis of the stay green gene in rice. Plant J 52:197-209

Kariola T, Brader G, Li J, Palva ET (2005) Chlorophyllase 1, a damage control enzyme, affects the balance between defense pathways in plants. Plant Cell 17:282-294

Kräutler B (2003) Chlorophyll breakdown and chlorophyll catabolites. In: Kadish KM, Smith KM, Guilard R (eds) The Porphyrin Handbook, vol 13. Elsevier Science, Amsterdam, pp 183-209

Kräutler B (2008) Chlorophyll breakdown and chlorophyll catabolites in leaves and fruit. Photochem Photobiol Sci 7:1114-1120

Kräutler B, Banala S, Moser S, Vergeiner C, Müller T, Lütz C, Holzinger A (2010) A novel blue fluorescent chlorophyll catabolite accumulates in senescent leaves of the peace lily and indicates a divergent path of chlorophyll breakdown. FEBS Lett 584:4215-4221

Kräutler B, Hörtensteiner S (2006) Chlorophyll catabolites and the biochemistry of chlorophyll breakdown. In: Grimm B, Porra R, Rüdiger W, Scheer H (eds) Chlorophylls and Bacteriochlorophylls: Biochemistry, Biophysics, Functions and Applications, vol 25. Advances in Photosynthesis and Respiration. Springer, Dordrecht, The Netherlands, pp 237-260

Kräutler B, Jaun B, Bortlik K-H, Schellenberg M, Matile P (1991) On the enigma of chlorophyll degradation: the constitution of a secoporphinoid catabolite. Angew Chem Int Ed Engl 30:13151318

Kunieda T, Amano T, Shioi Y (2005) Search for chlorophyll degradation enzyme, Mg-dechelatase, from extracts of Chenopodium album with native and artificial substrates. Plant Sci 169:177-183

Kusaba M, Ito H, Morita R, lida S, Sato Y, Fujimoto M, Kawasaki S, Tanaka R, Hirochika H, Nishimura M, Tanaka A (2007) Rice NON-YELLOW COLORING1 is involved in light-harvesting complex II and grana degradation during leaf senescence. Plant Cell 19:1362-1375

Langmeier M, Ginsburg S, Matile P (1993) Chlorophyll breakdown in senescent leaves: demonstration of Mg-dechelatase activity. Physiol Plant 89:347-353 
Liao Y, An K, Zhou X, Chen W-J, Kuai B-K (2007) AtCLH2, a typical but possibly distinctive chlorophyllase gene in Arabidopsis. J Integr Plant Biol 49:531-539

Lim PO, Kim HJ, Nam HG (2007) Leaf senescence. Annu Rev Plant Biol 58:115-136

Losey FG, Engel N (2001) Isolation and characterization of a urobilinogenoidic chlorophyll catabolite from Hordeum vulgare L. J Biol Chem 276:27233-27236

Lu Y-P, Li Z-S, Drozdowicz Y-M, Hörtensteiner S, Martinoia E, Rea PA (1998) AtMRP2, an Arabidopsis ATP binding cassette transporter able to transport glutathione S-conjugates and chlorophyll catabolites: functional comparisons with AtMRP1. Plant Cell 10:267-282

Lundquist PK, Poliakov A, Bhuiyan NH, Zybailov B, Sun Q, van Wijk KJ (2012) The functional network of the Arabidopsis plastoglobule proteome based on quantitative proteomics and genome-wide coexpression analysis. Plant Physiol 158:1172-1192

Mach JM, Castillo AR, Hoogstraten R, Greenberg JT (2001) The Arabidopsis-accelerated cell death gene ACD2 encodes red chlorophyll catabolite reductase and suppresses the spread of disease symptoms. Proc Natl Acad Sci USA 98:771-776

Matile P, Ginsburg S, Schellenberg M, Thomas H (1988) Catabolites of chlorophyll in senescing barley leaves are localized in the vacuoles of mesophyll cells. Proc Natl Acad Sci USA 85:9529-9532

Matile P, Hörtensteiner S, Thomas H (1999) Chlorophyll degradation. Annu Rev Plant Physiol Plant Mol Biol 50:67-95

Matile P, Schellenberg M (1996) The cleavage of pheophorbide $a$ is located in the envelope of barley gerontoplasts. Plant Physiol Biochem 34:55-59

Matile P, Schellenberg M, Peisker C (1992) Production and release of a chlorophyll catabolite in isolated senescent chloroplasts. Planta 187:230-235

Mecey C, Hauck P, Trapp M, Pumplin N, Plovanich A, Yao J, He SY (2011) A critical role of STAYGREEN/Mendel's I locus in controlling disease symptom development during Pseudomonas syringae pv tomato infection of Arabidopsis. Plant Physiol 157:1965-1974

Meguro M, Ito H, Takabayashi A, Tanaka R, Tanaka A (2011) Identification of the 7-hydroxymethyl chlorophyll $a$ reductase of the chlorophyll cycle in Arabidopsis. Plant Cell 23:3442-3453

Mochizuki N, Tanaka R, Grimm B, Masuda T, Moulin M, Smith AG, Tanaka A, Terry MJ (2010) The cell biology of tetrapyrroles: a life and death struggle. Trends Plant Sci 15:488-498

Morita R, Sato $Y$, Masuda $Y$, Nishimura M, Kusaba M (2009) Defect in non-yellow coloring 3 , an $\alpha / \beta$ hydrolase-fold family protein, causes a stay-green phenotype during leaf senescence in rice. Plant J 59:940-952 
Moser S, Müller T, Ebert MO, Jockusch S, Turro NJ, Kräutler B (2008a) Blue luminescence of ripening bananas. Angew Chem Int Ed 47:8954-8957

Moser S, Müller T, Holzinger A, Lutz C, Jockusch S, Turro NJ, Kräutler B (2009) Fluorescent chlorophyll catabolites in bananas light up blue halos of cell death. Proc Natl Acad Sci USA 106:15538-15543

Moser S, Ulrich M, Müller T, Kräutler B (2008b) A yellow chlorophyll catabolite is a pigment of the fall colours. Photochem Photobiol Sci 7:1577-1581

Mühlecker W, Kräutler B (1996) Breakdown of chlorophyll: constitution of nonfluorescing chlorophyllcatabolites from senescent cotyledons of the dicot rape. Plant Physiol Biochem 34:61-75

Mühlecker W, Kräutler B, Moser D, Matile P, Hörtensteiner S (2000) Breakdown of chlorophyll: a fluorescent chlorophyll catabolite from sweet pepper (Capsicum annuum). Helv Chim Acta 83:278-286

Mühlecker W, Ongania K-H, Kräutler B, Matile P, Hörtensteiner S (1997) Tracking down chlorophyll breakdown in plants: elucidation of the constitution of a 'fluorescent' chlorophyll catabolite. Angew Chem Int Ed Engl 36:401-404

Müller T, Moser S, Ongania K-H, Pružinská A, Hörtensteiner S, Kräutler B (2006) A divergent path of chlorophyll breakdown in the model plant Arabidopsis thaliana. ChemBioChem 7:40-42

Müller T, Rafelsberger M, Vergeiner C, Kräutler B (2011) A dioxobilane as product of a divergent path of chlorophyll breakdown in Norway maple. Angew Chem Int Ed 50:10724-10727

Müller T, Ulrich M, Ongania KH, Kräutler B (2007) Colorless tetrapyrrolic chlorophyll catabolites found in ripening fruit are effective antioxidants. Angew Chem Int Ed 46:8699-8702

Mur LAJ, Aubry S, Mondhe M, Kingston-Smith A, Gallagher J, Timms-Taravella E, James C, Papp I, Hörtensteiner S, Thomas H, Ougham H (2010) Accumulation of chlorophyll catabolites photosensitizes the hypersensitive response elicited by Pseudomonas syringae in Arabidopsis. New Phytol 188:161-174

Obayashi T, Hayashi S, Saeki M, Ohta H, Kinoshita K (2009) ATTED-II provides coexpressed gene networks for Arabidopsis. Nucl Acids Res 37:D987-D991

Oberhuber M, Berghold J, Breuker K, Hörtensteiner S, Kräutler B (2003) Breakdown of chlorophyll: a nonenzymatic reaction accounts for the formation of the colorless "nonfluorescent" chlorophyll catabolites. Proc Natl Acad Sci USA 100:6910-6915

Oberhuber M, Berghold J, Mühlecker W, Hörtensteiner S, Kräutler B (2001) Chlorophyll breakdown - on a nonfluorescent chlorophyll catabolite from spinach. Helv Chim Acta 84:2615-2627

Oh MH, Moon YH, Lee CH (2003) Increased stability of LHCII by aggregate formation during dark-induced leaf senescence in the Arabidopsis mutant, ore10. Plant Cell Physiol 44:1368-1377 
Park S-Y, Yu J-W, Park J-S, Li J, Yoo S-C, Lee N-Y, Lee S-K, Jeong S-W, Seo HS, Koh H-J, Jeon J-S, Park Y-I, Paek N-C (2007) The senescence-induced staygreen protein regulates chlorophyll degradation. Plant Cell 19:1649-1664

Pattanayak GK, Venkataramani S, Hörtensteiner S, Kunz L, Christ B, Moulin M, Smith AG, Okamoto Y, Tamiaki H, Sugishima M, Greenberg JT (2012) ACCELERATED CELL DEATH 2 suppresses mitochondrial oxidative bursts and modulates cell death in Arabidopsis. Plant J 69:589-600

Pružinská A, Anders I, Aubry S, Schenk N, Tapernoux-Lüthi E, Müller T, Kräutler B, Hörtensteiner S (2007) In vivo participation of red chlorophyll catabolite reductase in chlorophyll breakdown. Plant Cell 19:369-387

Pružinská A, Anders I, Tanner G, Roca M, Hörtensteiner S (2003) Chlorophyll breakdown: pheophorbide $a$ oxygenase is a Rieske-type iron-sulfur protein, encoded by the accelerated cell death 1 gene. Proc Natl Acad Sci USA 100:15259-15264

Pružinská A, Tanner G, Aubry S, Anders I, Moser S, Müller T, Ongania K-H, Kräutler B, Youn J-Y, Liljegren SJ, Hörtensteiner S (2005) Chlorophyll breakdown in senescent Arabidopsis leaves: characterization of chlorophyll catabolites and of chlorophyll catabolic enzymes involved in the degreening reaction. Plant Physiol 139:52-63

Ren G, An K, Liao Y, Zhou X, Cao Y, Zhao H, Ge X, Kuai B (2007) Identification of a novel chloroplast protein AtNYE1 regulating chlorophyll degradation during leaf senescence in Arabidopsis. Plant Physiol 144:1429-1441

Ren GD, Zhou Q, Wu SX, Zhang YF, Zhang LG, Huang JR, Sun ZF, Kuai BK (2010) Reverse genetic identification of CRN1 and its distinctive role in chlorophyll degradation in Arabidopsis. J Integr Plant Biol 52:496-504

Rodoni S, Vicentini F, Schellenberg M, Matile P, Hörtensteiner S (1997) Partial purification and characterization of red chlorophyll catabolite reductase, a stroma protein involved in chlorophyll breakdown. Plant Physiol 115:677-682

Sakuraba Y, Schelbert S, Park S-Y, Han S-H, Lee B-D, Besagni Andrès C, Kessler F, Hörtensteiner S, Paek NC (2012) STAY-GREEN and chlorophyll catabolic enzymes interact at light-harvesting complex II for chlorophyll detoxification during leaf senescence in Arabidopsis. Plant Cell 24:507-518

Sato Y, Moria R, Katsuma S, Nishimura M, Tanaka A, Kusaba M (2009) Two short-chain dehydrogenase/reductases, NON-YELLOW COLORING 1 and NYC1-LIKE, are required for chlorophyll $b$ and light-harvesting complex II degradation during senescence in rice. Plant J 57:120-131 
Sato Y, Morita R, Nishimura M, Yamaguchi H, Kusaba M (2007) Mendel's green cotyledon gene encodes a positive regulator of the chlorophyll-degrading pathway. Proc Natl Acad Sci USA 104:1416914174

Schelbert S, Aubry S, Burla B, Agne B, Kessler F, Krupinska K, Hörtensteiner S (2009) Pheophytin pheophorbide hydrolase (pheophytinase) is involved in chlorophyll breakdown during leaf senescence in Arabidopsis. Plant Cell 21:767-785

Schellenberg M, Matile P, Thomas H (1990) Breakdown of chlorophyll in chloroplasts of senescent barley leaves depends on ATP. J Plant Physiol 136:564-568

Schenk N, Schelbert S, Kanwischer M, Goldschmidt EE, Dörmann P, Hörtensteiner S (2007) The chlorophyllases AtCLH1 and AtCLH2 are not essential for senescence-related chlorophyll breakdown in Arabidopsis thaliana. FEBS Lett 581:5517-5525

Scheumann V, Schoch S, Rüdiger W (1998) Chlorophyll $a$ formation in the chlorophyll $b$ reductase reaction requires reduced ferredoxin. J Biol Chem 273:35102-35108

Scheumann V, Schoch S, Rüdiger W (1999) Chlorophyll $b$ reduction during senescence of barley seedlings. Planta 209:364-370

Schmidt CL, Shaw L (2001) A comprehensive phylogenetic analysis of Rieske and Rieske-type iron-sulfur proteins. J Bioenerg Biomembranes 33:9-26

Shioi Y, Tomita N, Tsuchiya T, Takamiya K (1996a) Conversion of chlorophyllide to pheophorbide by Mgdechelating substance in extracts of Chenopodium album. Plant Physiol Biochem 34:41-47

Shioi Y, Watanabe K, Takamiya K (1996b) Enzymatic conversion of pheophorbide $a$ to a precursor of pyropheophorbide $a$ in leaves of Chenopodium album. Plant Cell Physiol 37:1143-1149

Spassieva S, Hille J (2002) A lesion mimic phenotype in tomato obtained by isolating and silencing an LIs1 homologue. Plant Sci 162:543-549

Sugishima M, Kitamori Y, Noguchi M, Kohchi T, Fukuyama K (2009) Crystal structure of red chlorophyll catabolite reductase: enlargement of the ferredoxin-dependent bilin reductase family. J Mol Biol 389:376-387

Sugishima M, Okamoto Y, Noguchi M, Kohchi T, Tamiaki H, Fukuyama K (2010) Crystal structures of the substrate-bound forms of red chlorophyll catabolite reductase: implications for site-specific and stereospecific reaction. J Mol Biol 402:879-891

Suzuki T, Shioi Y (2002) Re-examination of Mg-dechelation reaction in the degradation of chlorophylls using chlorophyllin $a$ as substrate. Photosynth Res 74:217-223

Suzuki Y, Amano T, Shioi $Y$ (2006) Characterization and cloning of the chlorophyll-degrading enzyme pheophorbidase from cotyledons of radish. Plant Physiol 140:716-725 
Takamiya K, Tsuchiya T, Ohta H (2000) Degradation pathway(s) of chlorophyll: what has gene cloning revealed? Trends Plant Sci 5:426-431

Tanaka A, Tanaka R (2006) Chlorophyll metabolism. Curr Opin Plant Biol 9:248-255

Tanaka R, Hirashima M, Satoh S, Tanaka A (2003) The Arabidopsis-accelerated cell death gene ACD1 is involved in oxygenation of pheophorbide $a$ : inhibition of pheophorbide $a$ oxygenase activity does not lead to the "stay-green" phenotype in Arabidopsis. Plant Cell Physiol 44:1266-1274

Tanaka R, Tanaka A (2007) Tetrapyrrole biosynthesis in higher plants. Annu Rev Plant Biol 58:321-346

Tang L, Okazawa A, Itoh Y, Fukusaki E, Kobayashi A (2004) Expression of chlorophyllase is not induced during autumnal yellowing in Ginkgo biloba. Z Naturforsch C 59:415-420

Thomas H, Huang L, Young M, Ougham H (2009) Evolution of plant senescence. BMC Evolution Biol 9:163

Tommasini R, Vogt E, Fromenteau M, Hörtensteiner S, Matile P, Amrhein N, Martinoia E (1998) An ABC transporter of Arabidopsis thaliana has both glutathione-conjugate and chlorophyll catabolite transport activity. Plant J 13:773-780

Tsuchiya T, Ohta H, Okawa K, Iwamatsu A, Shimada H, Masuda T, Takamiya K (1999) Cloning of chlorophyllase, the key enzyme in chlorophyll degradation: finding of a lipase motif and the induction by methyl jasmonate. Proc Natl Acad Sci USA 96:15362-15367

Tu SL, Chen HC, Ku LW (2008) Mechanistic studies of the phytochromobilin synthase HY2 from Arabidopsis. J Biol Chem 283:27555-27564

Tu SL, Gunn A, Toney MD, Britt RD, Lagarias JC (2004) Biliverdin reduction by cyanobacterial phycocyanobilin : ferredoxin oxidoreductase (PcyA) proceeds via linear tetrapyrrole radical intermediates. J Am Chem Soc 126:8682-8693

Uauy C, Distelfeld A, Fahima T, Blechl A, Dubcovsky J (2006) A NAC gene regulating senescence improves grain protein, zinc, and iron content in wheat. Science 314:1298-1301

Van der Graaff E, Schwacke R, Schneider A, Desimone M, Flugge UI, Kunze R (2006) Transcription analysis of Arabidopsis membrane transporters and hormone pathways during developmental and induced leaf senescence. Plant Physiol 141:776-792

Vicentini F, Hörtensteiner S, Schellenberg M, Thomas H, Matile P (1995a) Chlorophyll breakdown in senescent leaves: identification of the biochemical lesion in a stay-green genotype of Festuca pratensis Huds. New Phytol 129:247-252

Vicentini F, Iten F, Matile P (1995b) Development of an assay for Mg-dechelatase of oilseed rape cotyledons, using chlorophyllin as the substrate. Physiol Plant 94:57-63

Wu A, Allu AD, Garapati P, Siddiqui H, Dortay H, Zanor MI, Asensi-Fabado MA, Munne-Bosch S, Antonio C, Tohge T, Fernie AR, Kaufmann K, Xue GP, Mueller-Roeber B, Balazadeh S (2012) 
JUNGBRUNNEN1, a reactive oxygen species-responsive NAC transcription factor, regulates longevity in Arabidopsis. Plant Cell 24:482-506

Wüthrich KL, Bovet L, Hunziker PE, Donnison IS, Hörtensteiner S (2000) Molecular cloning, functional expression and characterisation of RCC reductase involved in chlorophyll catabolism. Plant J 21:189-198

Yao N, Eisfelder BJ, Marvin J, Greenberg JT (2004) The mitochondrion - an organelle commonly involved in programmed cell death in Arabidopsis thaliana. Plant J 40:596-610

Yao N, Greenberg JT (2006) Arabidopsis ACCELERATED CELL DEATH2 modulates programmed cell death. Plant Cell 18:397-411

Zhang X, Zhang Z, Li J, Wu L, Guo J, Ouyang L, Xia Y, Huang X, Pang X (2011) Correlation of leaf senescence and gene expression/activities of chlorophyll degradation enzymes in harvested Chinese flowering cabbage (Brassica rapa var. parachinensis). J Plant Physiol 168:2081-2087

Zhou C, Han L, Pislariu C, Nakashima J, Fu C, Jiang Q, Quan L, Blancaflor EB, Tang Y, Bouton JH, Udvardi M, Xia G, Wang ZY (2011) From model to crop: functional analysis of a STAY-GREEN gene in the model legume Medicago truncatula and effective use of the gene for alfalfa improvement. Plant Physiol 157:1483-1496

Ziegler R, Blaheta A, Guha N, Schönegge B (1988) Enzymatic formation of pheophorbide and pyropheophorbide during chlorophyll degradation in a mutant of Chlorella fusca SHIRIA et KRAUS. J Plant Physiol 132:327-332

Zimmermann P, Hirsch-Hoffmann M, Hennig L, Gruissem W (2004) GENEVESTIGATOR. Arabidopsis microarray database and analysis toolbox. Plant Physiol 136:2621-2632 
Table 1 List of FCCs, NCCs and UCCs identified from higher plants

\begin{tabular}{|c|c|c|c|c|c|c|c|}
\hline Name & $\mathrm{R}^{1 \mathrm{c}}$ & $R^{2 c}$ & $R^{3 c}$ & $R^{4 c}$ & C1-epimer ${ }^{d}$ & Source $^{\mathrm{e}}$ & Reference \\
\hline \multicolumn{8}{|l|}{$p \mathrm{FCCs}$} \\
\hline$p F C C$ & $\mathrm{H}$ & $\mathrm{CH}_{3}$ & vinyl & $\mathrm{H}$ & 1 & $E$ & (Mühlecker et al. 1997) \\
\hline epi-pFCC & $\mathrm{H}$ & $\mathrm{CH}_{3}$ & vinyl & $\mathrm{H}$ & epi & $E$ & (Mühlecker et al. 2000) \\
\hline \multicolumn{8}{|l|}{$m \mathrm{FCCs}$} \\
\hline$A t-\mathrm{FCC}-1^{\mathrm{a}}$ & $\mathrm{OH}$ & $\mathrm{H}$ & vinyl & $\mathrm{H}$ & 1 & L & Pružinská et al. (2005) \\
\hline$A t-\mathrm{FCC}-2^{\mathrm{a}}$ & $\mathrm{H}$ & $\mathrm{H}$ & vinyl & $\mathrm{H}$ & 1 & L & Pružinská et al. (2005) \\
\hline \multicolumn{8}{|l|}{$h \mathrm{FCCs}$} \\
\hline$M c-F C C-49^{b}$ & O-glucosyl & $\mathrm{CH}_{3}$ & vinyl & daucic acid & epi & $\mathrm{F}$ & Moser et al. (2009) \\
\hline$M c-F C C-56^{b}$ & $\mathrm{OH}$ & $\mathrm{CH}_{3}$ & vinyl & daucic acid & epi & $\mathrm{F}$ & Moser et al. (2008a) \\
\hline$M a-F C C-61^{b}$ & $\mathrm{OH}$ & $\mathrm{CH}_{3}$ & vinyl & digalactosylglyceryl & epi & L & Banala et al. (2010) \\
\hline$S w-F C C-62^{b}$ & $\mathrm{OH}$ & $\mathrm{CH}_{3}$ & vinyl & dihydroxyphenylethylglucosyl & 1 & L & Kräutler et al. (2010) \\
\hline \multicolumn{8}{|l|}{ NCCs } \\
\hline At-NCC-1 ${ }^{\text {a }}$ & O-glucosyl & $\mathrm{H}$ & vinyl & $\mathrm{H}$ & 1 & L & Pružinská et al. (2005) \\
\hline At-NCC- ${ }^{\text {a }}$ & $\mathrm{OH}$ & $\mathrm{H}$ & vinyl & $\mathrm{H}$ & 1 & L & Pružinská et al. (2005) \\
\hline At-NCC-3 ${ }^{\text {a }}$ & $\mathrm{OH}^{\mathrm{f}}$ & $\mathrm{H}$ & vinyl & $\mathrm{H}$ & 1 & L & Pružinská et al. (2005) \\
\hline At-NCC- $4^{\text {a }}$ & O-glucosyl & $\mathrm{CH}_{3}$ & vinyl & $\mathrm{H}$ & 1 & L & Pružinská et al. (2005) \\
\hline At-NCC- $5^{\text {a }}$ & $\mathrm{H}$ & $\mathrm{H}$ & vinyl & $\mathrm{H}$ & 1 & L & Pružinská et al. (2005) \\
\hline$B n-N C C-1^{a}$ & O-malonyl & $\mathrm{H}$ & vinyl & $\mathrm{H}$ & 1 & L & Mühlecker and Kräutler (1996) \\
\hline$B n-N C C-2^{a}$ & $O$-glucosyl & $\mathrm{H}$ & vinyl & $\mathrm{H}$ & 1 & $\mathrm{~L}$ & Mühlecker and Kräutler (1996) \\
\hline$B n-N C C-3^{a}$ & $\mathrm{OH}$ & $\mathrm{H}$ & vinyl & $\mathrm{H}$ & 1 & $\mathrm{~L}$ & Mühlecker and Kräutler (1996) \\
\hline$B n-N C C-4{ }^{a}$ & $\mathrm{H}$ & $\mathrm{H}$ & vinyl & $\mathrm{H}$ & 1 & $\mathrm{~L}$ & Pružinská et al. (2005) \\
\hline Cj-NCC-1 ${ }^{\text {a }}$ & $\mathrm{OH}$ & $\mathrm{CH}_{3}$ & vinyl & $\mathrm{H}$ & epi & L & Curty and Engel (1996) \\
\hline
\end{tabular}




\begin{tabular}{|c|c|c|c|c|c|c|c|}
\hline$C j-\mathrm{NCC}-2^{\text {a }}$ & $\mathrm{H}$ & $\mathrm{CH}_{3}$ & vinyl & $\mathrm{H}$ & epi & $\mathrm{L}$ & Oberhuber et al. (2003) \\
\hline$H v-N C C-1^{\text {a }}$ & $\mathrm{OH}$ & $\mathrm{CH}_{3}$ & dihydroxyethyl & H & 1 & L & Kräutler et al. (1991) \\
\hline Lo-NCC-1 ${ }^{\text {a }}$ & $\mathrm{OH}$ & $\mathrm{CH}_{3}$ & vinyl & $\mathrm{H}$ & nd & L & Iturraspe et al. (1995) \\
\hline$L s-N C C-1^{\text {a }}$ & $\mathrm{OH}$ & $\mathrm{CH}_{3}$ & vinyl & $\mathrm{H}$ & nd & L & Iturraspe et al. (1995) \\
\hline Ms-NCC- $2^{\text {a }}$ & $\mathrm{OH}$ & $\mathrm{CH}_{3}$ & vinyl & $\mathrm{H}$ & epi & $\mathrm{F}$ & Müller et al. (2007) \\
\hline$N r-N C C-1^{a}$ & O-glucosylmalonyl & $\mathrm{CH}_{3}$ & vinyl & $\mathrm{H}$ & epi & $\mathrm{L}$ & Berghold et al. (2004) \\
\hline$N r-N C C-2^{a}$ & O-glucosyl & $\mathrm{CH}_{3}$ & vinyl & $\mathrm{H}$ & epi & L & Berghold et al. (2004) \\
\hline$P c-N C C-1^{a}$ & O-glucosyl & $\mathrm{CH}_{3}$ & vinyl & $\mathrm{H}$ & epi & $\mathrm{F}$ & Müller et al. (2007) \\
\hline PC-NCC-2 a & $\mathrm{OH}$ & $\mathrm{CH}_{3}$ & vinyl & $\mathrm{H}$ & epi & $\mathrm{F}$ & Müller et al. (2007) \\
\hline So-NCC-1 ${ }^{\text {a }}$ & $\mathrm{OH}$ & $\mathrm{H}$ & dihydroxyethyl & H & epi & L & Berghold et al. (2002) \\
\hline So-NCC- $2^{\text {a }}$ & $\mathrm{OH}$ & $\mathrm{CH}_{3}$ & dihydroxyethyl & $\mathrm{H}$ & epi & L & Oberhuber et al. (2001) \\
\hline So-NCC-3 a & $\mathrm{OH}$ & $\mathrm{H}$ & vinyl & $\mathrm{H}$ & epi & L & Berghold et al. (2002) \\
\hline So-NCC-4 ${ }^{\text {a }}$ & $\mathrm{OH}$ & $\mathrm{CH}_{3}$ & vinyl & $\mathrm{H}$ & epi & L & Berghold et al. (2002) \\
\hline So-NCC-5 a & $\mathrm{H}$ & $\mathrm{CH}_{3}$ & vinyl & $\mathrm{H}$ & epi & L & Berghold et al. (2002) \\
\hline SW-NCC-58 ${ }^{b}$ & $\mathrm{OH}$ & $\mathrm{CH}_{3}$ & vinyl & $\mathrm{H}$ & 1 & L & Kräutler et al. (2010) \\
\hline$Z m-N C C-1^{a}$ & O-glucosyl & $\mathrm{CH}_{3}$ & dihydroxyethyl & $\mathrm{H}$ & epi & L & Berghold et al. (2006) \\
\hline Zm-NCC- $2^{\text {a }}$ & O-glucosyl & $\mathrm{CH}_{3}$ & vinyl & $\mathrm{H}$ & epi & $\mathrm{L}$ & Berghold et al. (2006) \\
\hline \multicolumn{8}{|l|}{ UCCs } \\
\hline$H v-U C C-1{ }^{a, g}$ & $\mathrm{OH}$ & $\mathrm{CH}_{3}$ & dihydroxyethyl & $\mathrm{H}$ & 1 & L & (Losey and Engel 2001) \\
\hline$A p-U C C-1^{\mathrm{a}, \mathrm{g}}$ & $\mathrm{OH}$ & $\mathrm{CH}_{3}$ & dihydroxyethyl & $\mathrm{H}$ & epi & $\mathrm{L}$ & (Müller et al. 2011) \\
\hline
\end{tabular}

${ }^{a}$ A nomenclature for NCCs (and FCCs) has been defined (Ginsburg and Matile 1993) in which a prefix indicates the plant species and a suffix number indicates decreasing polarity in reversed-phase HPLC. ${ }^{b}$ These catabolites are indexed according to their retention time in HPLC analysis. Ap, Acer 
platanoides; At, Arabidopsis thaliana; Bn, Brassica napus; Cj, Cercidiphyllum japonicum; Hv, Hordeum vulgare; Lo, Liquidambar orientalis; Ls, Liquidambar styraciflua; Ma, Muca acuminate; Mc, Musa cavendish, Ms, Malus sylvestris; Nr, Nicotiana rustica; So, Spinacia oleracea; Zm, Zea mays ${ }^{c} R^{1}-R^{4}$ indicate residues at $C 3, C 8^{2}, C 13^{2}$ and $C 17^{3}$ side positions, respectively, of FCCs and NCCs as shown in Figure 1.

${ }^{d} \mathrm{C} 1$ stereochemistry refers to the type of $p \mathrm{FCC}$, i.e. $p \mathrm{FCC}(1)$ or epi-pFCC (epi), formed in the respective species or genus; nd, not determined ${ }^{e}$ source of material used for catabolite isolation: $E$, in vitro enzymatic PAO/RCCR assays; $F$, fruits; L, leaves

${ }^{f}$ In At-NCC-3, the site of hydroxylation is indicated to be C7 (rather than $C 8^{2}$ ) (Müller et al. 2006).

${ }^{\mathrm{g}} \mathrm{Hv}$-UCC-1 and Ap-UCC-1 are indicated to be pseudo-enantiomers (Müller et al. 2011). 
Figure legends:

\section{Figure 1}

The PAO pathway of chlorophyll breakdown. Depicted are the chemical structures of chlorophyll and of chlorophyll catabolites as well as chlorophyll catabolic enzymes involved in the pathway. Note that besides the linear PAO pathway ending in the formation of NCCs, divergent paths of the pathway have been proposed recently after the identification of UCCs and $h$ FCCs that occur as persistant catabolites in different plant species. Possibly these catabolites are derived from $p$ FCC. Pyrrole rings (A-D), the isocyclic ring $(\mathrm{E})$, methine bridges $(\alpha-\delta)$ and relevant carbon atoms are labeled in Chl $a \cdot \mathrm{R}^{1}-\mathrm{R}^{4}$ in FCCs, NCCs and UCCs indicate modifications as outlined in Table 1.

Chl, chlorophyll; HCAR, hydroxy-Chl a reductase; $h F C C$, hypermodified fluorescent Chl catabolite; MCS, metal chelating substance; $\mathrm{mFCC}$, modified fluorescent $\mathrm{Chl}$ catabolite; NCC, nonfluorescent $\mathrm{Chl}$ catabolite; NOL, NYC1-like; NYC1, non-yellow coloring1; PAO, Pheide $a$ oxygenase; $p F C C$, primary fluorescent Chl catabolite; Pheide, pheophorbide; PPH, pheophytinase; RCC, red Chl catabolite; RCCR, RCC reductase; UCC, urobilinogenoidic Chl catabolite.

\section{Figure 2}

Cellular model of the PAO pathway of chlorophyll breakdown. The model shows the main route of breakdown leading to the formation of NCCs. Within gerontoplasts, breakdown of Chl to $p F C C$ putatively occurs in a dynamic protein complex involving SGR and the Chl catabolic enzymes. Note, that interaction of HCAR with the other components has not yet been investigated and that the molecular nature of MCS is unknown. The model also indicates divergent paths identified in different plant species that lead to the formation of $h$ FCCS or UCCs. These catabolites possibly derive from $p F C C$ and possibly accumulate in the vacuole. ABC, ATP-binding cassette transporter; Carrier, putative catabolite transporter at the envelope; SGR, stay-green protein. For further abbreviations see the legend of Figure 1. Putative steps are labeled with a question mark. 

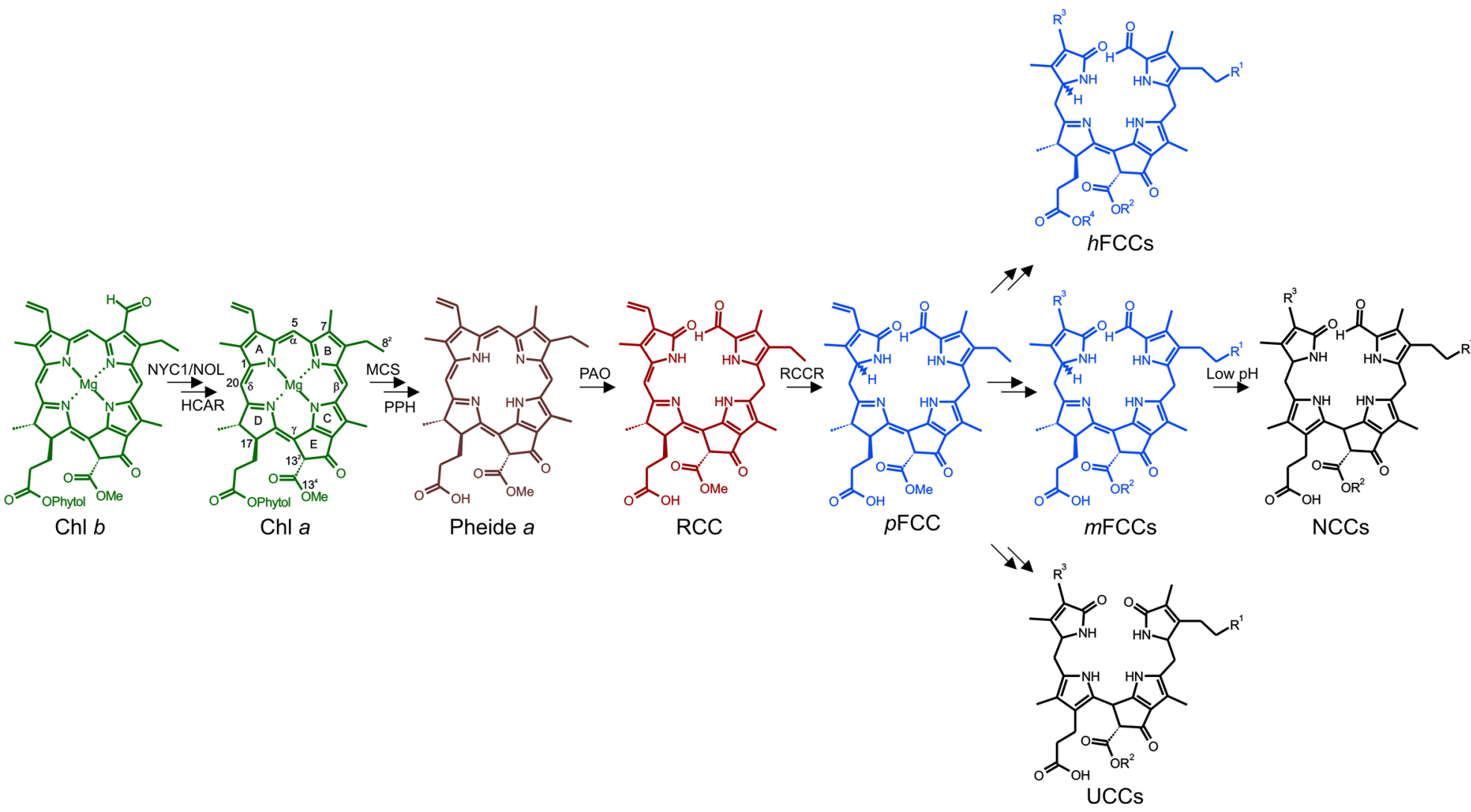


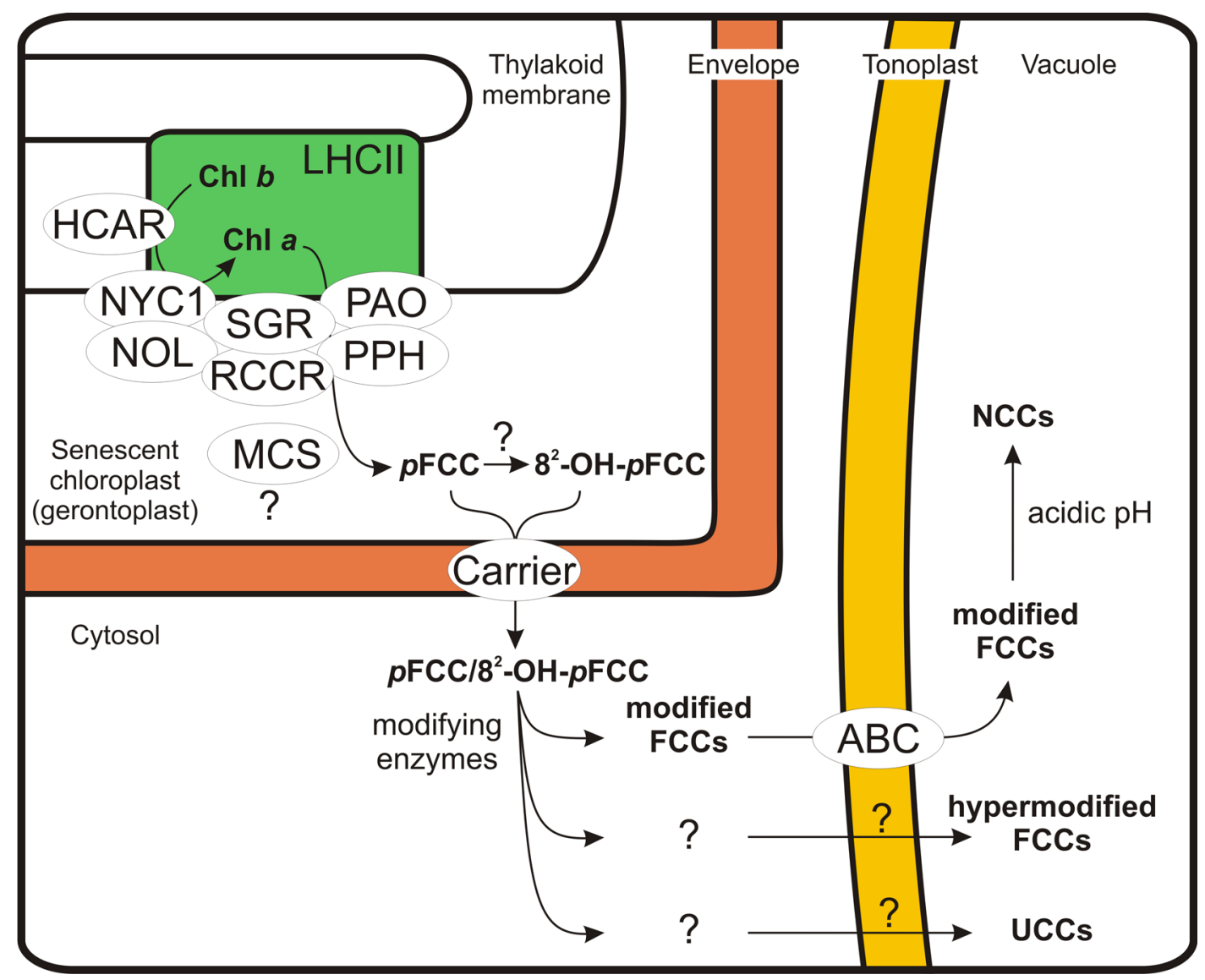

